\title{
Cubital tunnel syndrome - endoscopic-assisted anterior submuscular transposition of the ulnar nerve: A feasibility study using a cadaver model
}

\author{
Jamal A Mohammad MD FRCSC, Nahidh Hasaniya MD PhD, Saleh M Shenaq MD \\ Division of Plastic Surgery, Baylor College of Medicine, Houston, Texas, USA
}

\begin{abstract}
JA Mohammad, N Hasaniya, SM Shenaq. Cubital tunnel syndrome - endoscopic-assisted anterior submuscular transposition of the ulnar nerve: A feasibility study using a cadaver model. Can J Plast Surg 1999;7(4):173-177.

The purpose of this project was to perform endoscopic-assisted release of the ulnar nerve with submuscular transposition using a single $4 \mathrm{~cm}$ incision at the cubital tunnel level in fresh cadaver limbs. A successful cubital tunnel release decompression depends on the precise release of all potential entrapment points. Twelve fresh cadaver limbs (from six human cadavers) were used for this project. A $4 \mathrm{~cm}$ incision was made along the course of the ulnar nerve at the cubital tunnel. While the ulnar nerve was under constant magnified visualization and protection, all surrounding fascial tissues were released freely from the nerve. The medial intermuscular septum and arcade of Struthers were adequately visualized and divided. The overlying superficial fascia of flexor carpi ulnaris being dissected freely from the nerve, the nerve was transposed and repair of the flexor aponeurosis to the medial epicondyle was completed. Release of the ulnar nerve with submuscular transposition was accessible through one small skin incision with the aid of the endoscope. This new procedure may have clinical applications with a surgical outcome similar to the traditional approach. This technique prevents long scarring, decreases patient postoperative pain and shortens the rehabilitation period.
\end{abstract}

Key Words: Cubital tunnel syndrome; Submuscular transposition; Ulnar nerve

Syndrome du tunnel cubital -transposition antérieure sous-musculaire du nerf cubital par endoscopie : une étude de faisabilité au moyen d'un modèle cadavérique

RÉSUMÉ : Le but de ce projet était de libérer le nerf cubital par endoscopie en effectuant une transposition sous-musculaire à
travers une incision de $4 \mathrm{~cm}$ au niveau du tunnel cubital dans des membres de cadavres frais. Une décompression réussie du tunnel
cubital dépend d'une libération précise de tous les points potentiels d'englobement du nerf. Douze membres de cadavres frais
(provenant de six cadavres humains) ont été utilisés pour cette étude. Une incision de $4 \mathrm{~cm}$ a été pratiquée le long du trajet du nerf
cubital au niveau du tunnel cubital. Alors que le nerf cubital était constamment visualisé par grossissement et protégé, tous les tissus
aponévrotiques environnants ont été détachés du nerf. La cloison interne intermusculaire et l'arcade de Struther ont été adéquatement
visualisées et divisées. Après l'excision de l'aponévrose sus-jacente superficielle du muscle cubital antérieur, le nerf a été transposé
et la réparation de l'aponévrose du muscle fléchisseur a été complétée. La libération du nerf cubital par transposition sous-musculaire
a pu être pratiquée à travers une petite incision de la peau avec l'aide d'un endoscope. Cette nouvelle technique pourrait avoir les
mêmes applications cliniques et les mêmes résultats chirurgicaux que la technique conventionnelle. De plus, elle prévient une
période de cicatrisation longue, diminue la douleur postopératoire du patient et raccourcit la période de rééducation.

$\mathrm{I}_{\mathrm{n}}^{\mathrm{n}}$ the upper extremity, entrapment neuropathies of the ulnar nerve occur in two areas: at the elbow (cubital tunnel syndrome) and at the wrist in Guyon's canal (ulnar tunnel

This paper was presented at the 1998 Annual Meeting of the American Society for Peripheral Nerve, May 22 to 24, 1998, Vancouver, British Columbia

Correspondence and reprints: Dr Saleh M Shenaq, Division of Plastic Surgery, Baylor College of Medicine, 6560 Fannin, Suite 800, Houston, Texas 77030, USA. Telephone 713-798-6310, fax 713-798-3806,

e-mailsshenaq@bcm.tmc.edu syndrome). There are numerous sites in the elbow at which the ulnar nerve may be compressed or injured. These sites include the arcade of Struthers (1), the medial intermuscular septum (1), adjacent to osteophyte or areas of synovitis at the medial epicondyle (2), the medial head of the triceps (3) and near the deep flexor pronator aponeurosis $(2,4)$. At the elbow, ulnar neuropathy may result in severe impairment of hand function secondary to pain, parasthesia and loss of motor function. Electrodiagnostic findings consistent with decrease in conduction velocity and denervation may be present. 


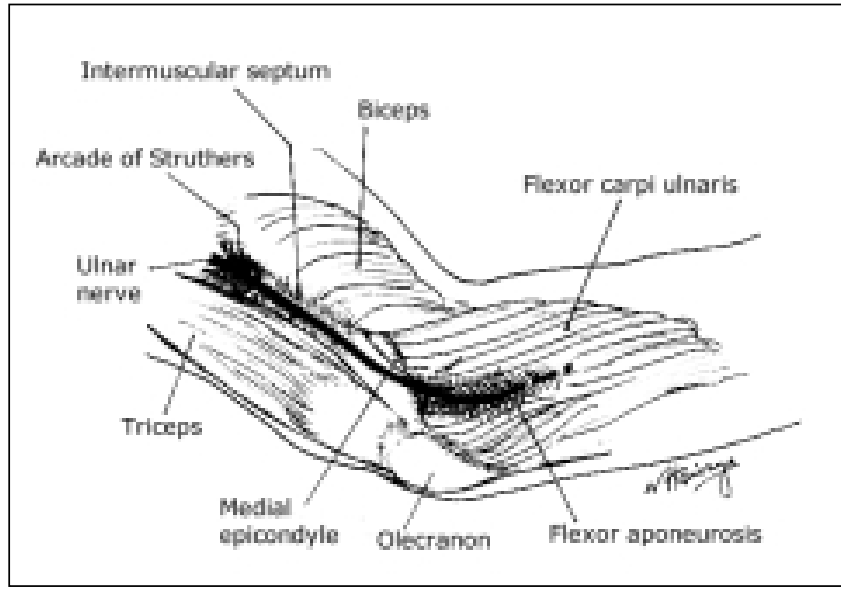

Figure 1) Illustration of the ulnar nerve in the elbow with location of the potential compression sites of the nerve in this region

Factors predisposing patients to cubital tunnel syndrome include trauma, fractures, ganglions or congenitally sublaxating nerve $(2,5)$. Surgery is usually indicated when the patient has sensory symptoms (ie, a positive percussion test over the ulnar nerve accompanied by reduction in the electrodiagnostic study parameters). The successful final outcome of a surgical decompression of the ulnar nerve depends on the adequate and complete release of all potential entrapment points.

Suggested surgical techniques of ulnar nerve decompression at the cubital tunnel include simple in situ decompression of the ulnar nerve $(6,7)$, anterior transposition of the ulnar nerve (subcutaneous [4,8], intermuscular [9] and submuscular $[2,10])$ and medial epicondylectomy of the humerus (3). Each technique is associated with certain advantages and disadvantages (11). The correct surgical method of treating cubital tunnel syndrome is still an area of great controversy.

In recent years, minimal access surgery using endoscopic techniques has found new application in various surgical fields. This endoscopic technique may offer many advantages over previous open techniques, such as minimization of the resultant scar, lessening of postoperative patient discomfort and a shorter recovery time. In endoscopic surgery, the clear magnified visualization of the anatomical structures provides the surgeon with the ability to identify each structure with accuracy. The endoscope has been used safely in clinical practice. Endoscopic carpal tunnel decompression of the median nerve during the past few years has been correlated with good results and patient satisfaction (12-15).

The authors successfully attempted a feasibility endoscopic technique combined with an open approach to transpose the ulnar nerve in the submuscular level. The surgical technique and instruments used are described.

\section{SURGICAL ANATOMY}

Numerous published studies have described in great detail the surgical anatomy of the ulnar nerve in the upper extremity $(1,10,11,16-23)$. The ulnar nerve rises from the eighth cervi-

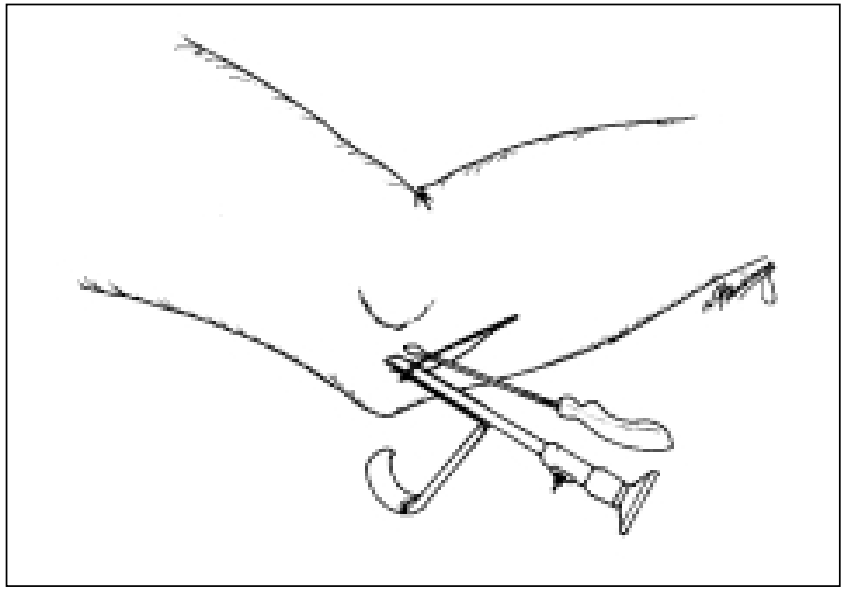

Figure 2) Location of the surgical incision at the cubital tunnel level

cal and first thoracic nerve roots, and becomes the main continuation of the medial cord of the brachial plexus. At the junction of the middle and distal thirds of the humerus, it pierces the medial intermuscular septum at the borders of the triceps and brachial muscles (Figure 1). The arcade of Struthers is a fascial thickening extending from the medial head of the triceps to the medial intermuscular septum. From the extensor surface of the arm, the ulnar nerve passes to the flexor surface of the forearm within the cubital tunnel. The cubital tunnel is a fibro-osseous canal with distinct floor and roof structures. The floor of the canal is composed of the olecranon laterally, and the medial epicondyle and medial collateral ligament medially. The roof of this tunnel is formed by a fascial band that extends from the olecranon to the medial epicondyle and overlies the two heads of flexor carpi ulnaris (FCU). The ulnar nerve gives several articular sensory branches and two branches to the FCU. Inside the tunnel, multiple fascial layers cover the nerve. It then courses behind and beneath the medial epicondyle to lie beneath the fascial arcade joining the two heads of the FCU. The ulnar nerve then passes between these two heads to course on the volar surface of the flexor digitorum profundus (FDP) to the midportion of the forearm. This aponeurosis lines the deep surface of the FCU, separating it from the FDP and flexor digitorum superficialis.

The ulnar nerve has no muscular branches in the arm. At the elbow, it gives off muscular branches to the FCU and to the lateral aspect of the FDP.

\section{MATERIALS AND METHODS}

The endoscopic surgical procedure was performed at the anatomy laboratory of Baylor College of Medicine, Houston, Texas. Six fresh cadavers with 12 extremities were available for the study. A good knowledge of the anatomical course of the ulnar nerve in the upper extremity was established with previous anatomical dissection studies in preserved and fresh human cadavers.

The Snowden-Pencer endoplastic endoscopic setup (Snowden-Pencer Corp, Tucker, Georgia) was used for this 


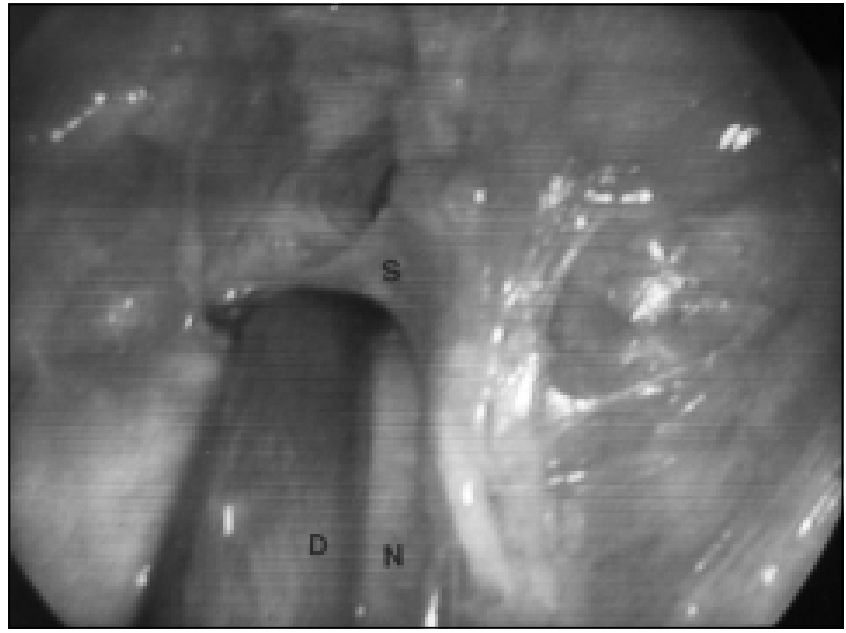

Figure 3) Proximal view of the ulnar nerve $(N)$ with its overlying medial intermuscular septum $(S)$ before endoscopic release. D Endoscopic instrument

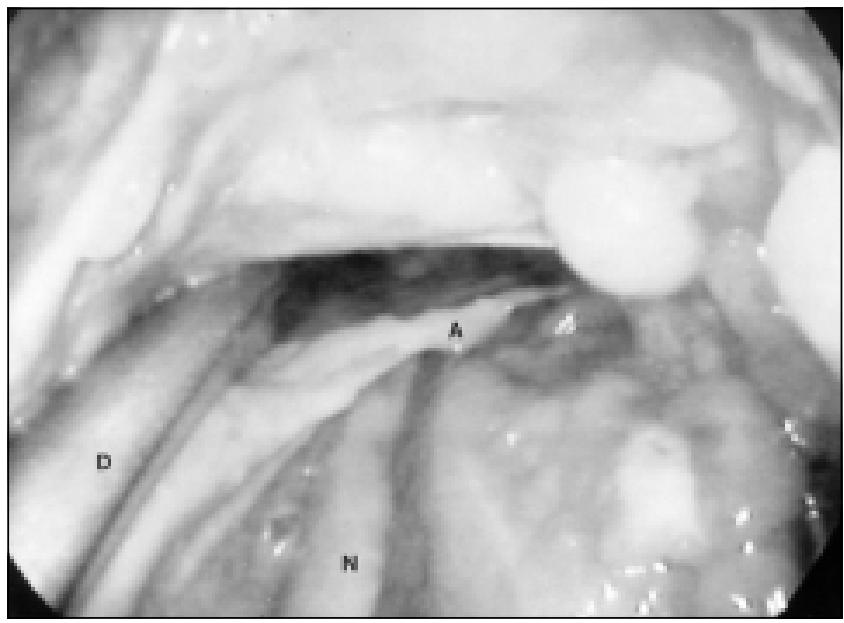

Figure 4) The ulnar nerve $(N)$ location under the arcade of Struthers $(A)$ before endoscopic release. D Distal

study. A $4 \mathrm{~mm}$ rigid endoscope with a $30^{\circ}$ angle lens was used for visualization. A medical-quality video camera transported the image to a television monitor, and the image was recorded on a video cassette recorder. Standard endoplastic endoscopic instruments were used, such as periosteal elevators, dissectors, nerve protectors and scissors. The Emory EndoPlastic $5 \mathrm{~mm}$ retractor (Karl Storz Endoscopy, Culver City, California) was used to aid in skin flap elevation and protection of the endoscope.

The surgical technique used in this study, through a single $4 \mathrm{~cm}$ incision, is a closed endoscopic method in combination with a traditional open surgical technique of anteriorsubmuscular transposition of the ulnar nerve.

A $4 \mathrm{~cm}$ incision was curved along the course of the ulnar nerve in the cubital tunnel and centred between the medial epicondyle and medial border of the olecranon (Figure 2). Subcutaneous dissection of the incision at the ulnar nerve was adequately identified, and open dissection was extended to $3 \mathrm{~cm}$ in both proximal and distal directions to the incision.

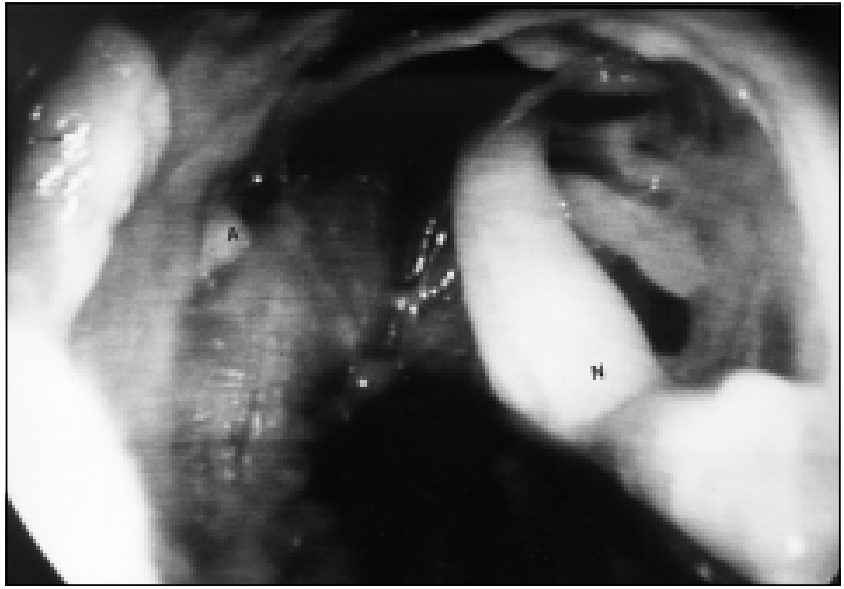

Figure 5) The ulnar nerve ( $N$ ) after release. A Arcade of Struthers

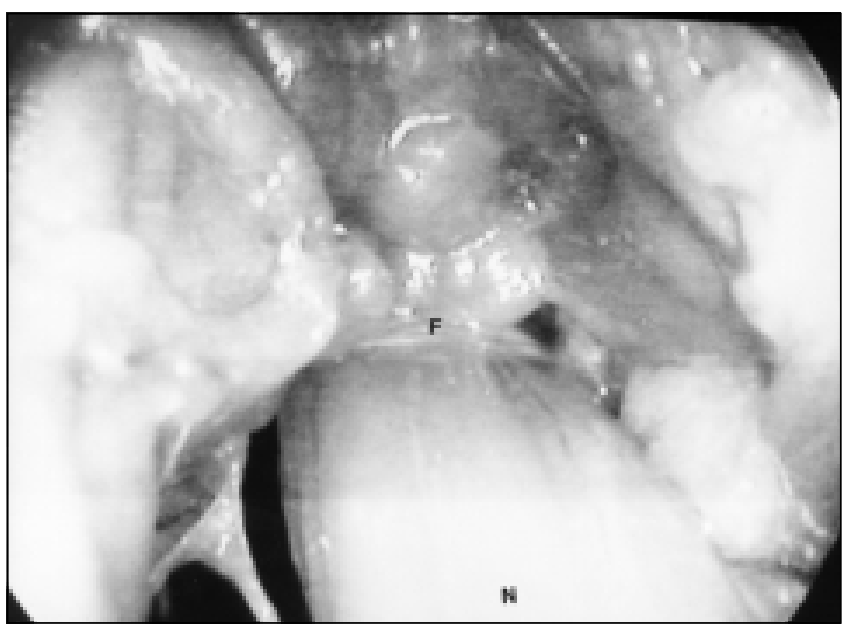

Figure 6) Distal view of the ulnar nerve $(N)$ below the fascial bands of the flexor carpi ulnaris $(F)$

Care was taken to avoid injury to the medial antebrachial nerve. The dissection was deepened, and the ulnar nerve was identified and exposed through the flexor aponeurosis. Open dissection of the ulnar nerve at this level provided surgical access for the endoscope. Initially, the structures proximal to the medial epicondyle were released. All the fascial structures covering the ulnar nerve were released through direct vision. A dilator was inserted proximally to create an optical field that was necessary for the initial endoscopic dissection of the nerve. The endoscopic retractor was inserted to elevate the proximal skin subcutaneous flap, and the endoscope was introduced through the retractor. A clear magnified picture of the ulnar nerve with its surrounding anatomical structures was viewed throughout the course of the procedure on the monitor. A blunt periosteal elevator was used to dissect the nerve from the overlying fibres of the medial intermuscular septum, and the septum was divided (Figure 3 ). The arcade of Struthers was identified as a well-formed, thick, fibrous structure covering the proximal portion of the ulnar nerve 

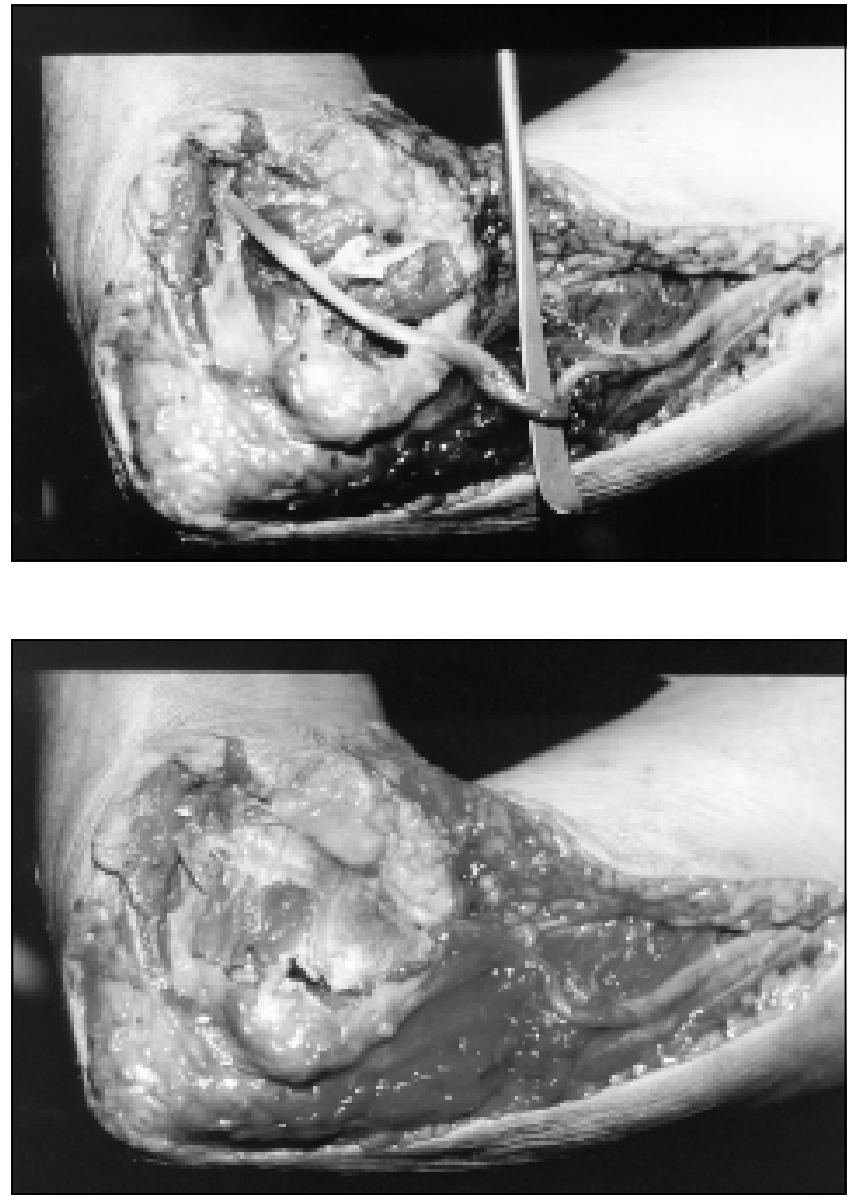

Figure 7) Top The ulnar nerve following transposition showing complete release of all entrapment points. Bottom The ulnar nerve showing anterior submuscular transposition

(Figure 4). This arcade was divided (Figure 5) and released completely under magnified vision with endoscopic scissors. After the ulnar nerve was exposed and released from at least $10 \mathrm{~cm}$ proximal to the medial epicondyle, the nerve was mobilized from its bed to assess the adequacy of the proximal endoscopic release.

After completion of the ulnar nerve release proximally, attention was focused on the distal structures. With assisted endoscopic magnified visualization, the overlying fibrous bands were divided and freed distally deep to the fascia overlying the two heads of the FCU (Figure 6).

The dilator was inserted, followed by the endoscope. Similar to proximal nerve release, the ulnar nerve was identified and dissected freely from its fibrous and vascular attachments. The motor nerve branch to the FCU was identified and protected. An endoscopic release of the nerve was carried into the proximal third of the forearm. At this stage, the ulnar nerve was ready to be mobilized completely anterior to the medial epicondyle. Adequate release was also assessed with the endoscope in distal and proximal directions. Following complete release and anterior transposition of the nerve, a traditional submuscular transposition of the nerve was easily made through the same incision. An L-shaped elevation of the common flexor muscles from the medial epicondyle was performed under direct vision using sharp dissection. Before this step, proper identification of the median nerve location in the brachium is essential. The muscle origin was reflected distally and the nerve transposed into its new submuscular position. The flexor aponeurosis to the medial epicondyle was repaired. Following transposition, the nerve was examined both proximally and distally with the endoscope for any residual sites of compression (Figure 7). The adequacy of ulnar nerve mobilization and transposition was also confirmed by wide local exploration of the skin flaps. No damage to the antebrachial cutaneous nerve was identified following the procedure.

\section{DISCUSSION}

Various decompression techniques for the surgical management of cubital tunnel syndrome have been used in clinical practice for more than 70 years $(2,6,7,9,10-11,16,19,20,23)$.

All of the current traditional surgical techniques of decompression of the ulnar nerve use a skin incision of more than 8 to $12 \mathrm{~cm}$. Potential complications may develop with this type of open surgical approach, such as medial antebrachial cutaneous nerve injury, hypertrophic long scars, and prolonged time of patient recovery and rehabilitation.

In this study, we combined both open and closed endoscopic surgical techniques for anterior submuscular transposition of the ulnar nerve through a single $4 \mathrm{~cm}$ incision. This avoids the potential disadvantages of using longer surgical incisions. With endoscopy, a magnified vision of the ulnar nerve and its surrounding structures provided a clear picture of the surgical anatomy of the ulnar nerve. All potential compression sites were easily identified and adequately released with the aid of the endoscope. Successful decompression of the nerve as much as $10 \mathrm{~cm}$ proximal to the medial epicondyle and to the proximal third of the forearm was achieved. By utilizing this endscopic technique, the $4 \mathrm{~cm}$ incision was sufficient for both endoscopic release of the ulnar nerve and submuscular transposition of the nerve. Few limitations are associated with this new technique. Endoscopic mobilization and dissection of the nerve are tedious and time consuming. Bleeding may present as a problem in live experimental subjects; however, certain surgical experience is required in performing this procedure in clinical practice. This is essential in order to avoid potential complications such as inadequate release of the nerve and subsequent recurrence of the cubital tunnel syndrome.

ACKNOWLEDEGMENTS: The authors thank Mr Greg Duncan of the Anatomy Laboratory, Baylor College of Medicine, for his assistance with anatomical preparation and Tory Crawford (Snowden-Pencer Corp, Tucker, Georgia) for his technical assistance with the endoscopic setup.

\section{REFERENCES}

1. Kane E, Kaplan EB, Spinner M. Observation of the course of the ulnar nerve in the arm. Ann Chir 1973;27:487-96.

2. Leffert RD. Anterior submuscular transposition of the ulnar nerves by the Learmomth technique. J Hand Surg [Am] 1982;7:147-55. 
3. Carven PR, Green DP. Cubital tunnel syndrome: Treatment by medial epicondylectomy. J Bone Joint Surg [Am] 1980;62:986-9.

4. Amadio PC, Beckenbaugh RD. Entrapment of the ulnar nerve by the deep flexor-pronator aponeurosis. J Hand Surg [Am] 1986,11:83-7.

5. Childress HM. Recurrent ulnar nerve dislocation at the elbow. Clin Orthop 1975;108:168-73.

6. Steiner HH, von Kaken MS, Stiener-Milz HG. Entrapment neuropathy at the cubital tunnel: simple decompression is the method of choice. Acta Neurochirurgica 1996;138:308-13.

7. LeRoux PD, Ensign TD, Burchiel KJ. Surgical decompression without transposition for ulnar neuropathy: factors determining outcome. Neurosurgery 1990;27:709-14.

8. Eaton RG, Crawe JF, Parkes JC. Anterior transposition of the ulnar nerve using a non-compression fasciodermal sling. J Bone Joint Surg [Am] 1980;62:820-5.

9. Kleinman WB, Bishop AT. Anterior intermuscular transposition of ulnar nerve. J Hand Surg [Am] 1989;14:972-9.

10. Broudy AS, Leffert RD, Smith RJ. Technical problems with the ulnar nerve transposition at the elbow: Findings and results of reoperations. J Hand Surg 1978;3:85-9.

11. Blair SJ. Avoiding complications of surgery for nerve compression syndromes. Orth Clin North Am 1988;19:125-30.

12. Chow JC. Endoscopic releases of the carpal ligament. A new technique for carpal tunnel syndrome. Arthroscopy 1989;5:11-8.

13. Chow JC. Endoscopic releases of the carpal ligament for carpal tunnel syndrome: 22 month clinical results. Arthroscopy 1990;6:288-96.
14. Agee JM, McCarrol HR, Tortosa RD, et al. Endoscopic release of the carpal tunnel: A randomized prospective multicenter study. J Hand Surg [Am] 1992;17:987-95.

15. Brown RA, Gelberman EH, Seiler JG, et al. Carpal tunnel release: A prospective randomized assessment of open and endoscopic methods. J Bone Joint Surg 1993;75:1265-75.

16. Tsai T, Bonczar M, Tsuruta T. A new operative technique: cubital tunnel decompression with endoscopic assistance. Hand Clin 1995;11:71-9.

17. McQuarrie IG. Peripheral nerve surgery - today and looking ahead. Clin PlasT Surg 1986;13:255-68.

18. Apfelberg DB, Larson SJ. Dynamic anatomy of the ulnar nerve at the elbow. Plast Reconstr Surg 1973;51:76-81.

19. Campbell WW, Pridgeon RM, Riaz G, et al. Variations in the anatomy of the ulnar nerve at the cubital tunnel: Pitfalls in the diagnosis of ulnar neuropathy at the elbow. Muscle Nerve 1991;14:733-8.

20. Eversman WW Jr. Entrapment and compression neuropathies. In: Green DP, ed. Operative Hand Surgery, 2nd edn. New York: Churchill Livingstone, 1988:1441-54.

21. Inserra S, Spinner M. An anatomic factor significant in transposition of the ulnar nerve. J Hand Surg [Am] 1986;11:80-7.

22. Adelaar RS, Foster WC, McDowell C. The treatment of the cubital tunnel syndrome. J Hand Surg [Am] 1984;9:90-5.

23. O'Driscoll SW, Horii E, Carmichael SW, Morrey BF. The cubital tunnel and ulnar neuropathy. J Bone Joint Surg [Br] 1991;73: 613-7. 